\title{
Pengaruh Optimalisasi Suhu Dan Waktu Pada Mesin Vacuum Frying Terhadap Peningkatan Kualitas Keripik Mangga Situbondo
}

\author{
Nely Ana Mufarida \\ Prodi Teknik Mesin, Fakultas Teknik, Universitas Muhammadiyah Jember \\ E-mail: nelyana@unmuhjember.ac.id
}

\begin{abstract}
ABSTRAK
Volume ekspor buah mangga selalu menurun dibandingkan dengan total produksinya karena kebutuhan konsumsi dalam negeri semakin tinggi. Akibatnya pada saat musim panen raya terjadi lonjakan produksi yang besar. Untuk mengatasi produksi yang berlimpah dan sifat buah mangga yang mudah rusak, maka dibutuhkan teknologi pengolahan dan penyimpanan agar masa distribusi lebih lama. Kondisi ini dapat dimanfaatkan oleh petani mangga untuk meningkatkan nilai tambah, daya saing dan kesejahteraan melalui kegiatan diversifikasi produk olahan buah mangga. Cara mendapatkan keripik buah dengan mutu tinggi adalah menggunakan mesin penggorengan vacuum frying. Kelebihannya antara lain keripik buah tidak gosong, kandungan nutrisi tidak hilang, rasa dan aroma sesuai bahan aslinya, renyah, tidak perlu bahan pengawet dan penambah rasa buatan. Rumusan masalah dalam penelitian ini adalah membahas pengaruh optimalisasi suhu dan waktu mesin vacuum frying terhadap peningkatan kualitas keripik mangga. Tujuan penelitian ini adalah untuk mengkaji pengaruh suhu dan waktu penggorengan dengan menggunakan mesin vacuum frying terhadap karakteristik mutu keripik mangga dan untuk menentukan suhu dan waktu penggorengan yang terbaik untuk pembuatan keripik mangga dengan penggorengan vacuum frying agar diperoleh produk keripik mangga yang sesuai dengan keinginan konsumen. Metode penelitian yang digunakan dalam penelitian ini adalah metode experimental nyata (true experimental research). Penelitian ini dilaksanakan di Laboratorium Permesinan Program Studi Teknik Mesin Universitas Muhammadiyah Jember Jalan Karimata No. 49 Jember pada bulan November 2017. Alat yang digunakan dalam penelitian ini adalah mesin vacuum frying kapasitas $2 \mathrm{~kg}$ bahan. Pengamatan suhu yang digunakan untuk melakukan penggorengan adalah $70^{\circ} \mathrm{C}, 80^{\circ} \mathrm{C}$, dan $90^{\circ} \mathrm{C}$ dan variasi waktunya adalah 30 menit, 40 menit, dan 50 menit sehingga diperoleh kualitas keripik mangga yang optimal berdasarkan uji organoleptik. Batasan masalah dalam penelitian ini adalah kadar air buah-buahan yang digoreng sebesar $60 \%$ $85 \%$, kapasitas maksimal tabung penggoreng $2 \mathrm{~kg}$ dengan kebutuhan minyak goreng sebanyak 12 liter. Penentuan perlakuan suhu dan waktu penggorengan yang terbaik dari hasil uji organoleptik dengan uji pembobotan. Pada uji organoleptik, panelis dimintai pendapatnya mengenai tingkat kesukaannya terhadap produk keripik mangga. Uji organoleptik pada penelitian ini menggunakan 15 orang panelis dengan uji kesukaan meliputi 4 parameter mutu yaitu aroma, rasa, kerenyahan, dan warna. Hasil dari penelitian ini adalah perlakuan suhu dan waktu penggorengan yang terbaik untuk pembuatan keripik mangga adalah suhu $90^{\circ} \mathrm{C}$ selama 50 menit. Hasil kuisioner menunjukkan bahwa panelis cenderung mengurutkan kerenyahan pada urutan pertama (38\%), rasa pada urutan kedua (33.33\%), warna pada urutan ketiga (29.33\%), dan aroma pada urutan keempat $(26.66 \%)$.
\end{abstract}

Kata Kunci: vacuum frying, keripik manga, optimalisasi suhu

\begin{abstract}
The export volume of mangoes always decreases compared to the total production because domestic consumption needs are getting higher. As a result, during the harvest season a large production surge occurs. To overcome the abundant production and the easily damaged nature of mangoes, processing and storage technology is needed so that the distribution period is longer This condition can be utilized by mango farmers to increase added value, competitiveness and welfare through diversification of processed mango products. How to get high quality fruit chips
\end{abstract}


is to use a vacuum frying frying machine. The advantages include non-charred fruit chips, nutrient content not lost, taste and aroma according to the original ingredients, crispy, no need for preservatives and artificial flavor enhancers. The formulation of the problem in this study is to discuss the effect of optimizing the temperature and time of vacuum frying machines on improving the quality of mango chips. The purpose of this study was to examine the effect of temperature and time of frying using a vacuum frying machine on the quality characteristics of mango chips and to determine the best temperature and time of frying for the manufacture of mango chips with vacuum frying to obtain mango chips according to consumer desires. The research method used in this research is true experimental research. This research was conducted at the Laboratory of Engineering, Mechanical Engineering Study Program, Muhammadiyah Jember University, Jalan Karimata No. 49 Jember in November 2017. The tool used in this study is a vacuum frying machine with a capacity of $2 \mathrm{~kg}$ of material. Temperature observations used for frying were $70^{\circ} \mathrm{C}, 80^{\circ} \mathrm{C}$, and $90^{\circ} \mathrm{C}$ and the time variations were 30 minutes, 40 minutes, and 50 minutes so that the optimum quality of mango chips was obtained based on organoleptic tests. The limitation of the problem in this study is the fruity moisture content of $60 \%-85 \%$, the maximum capacity of $2 \mathrm{~kg}$ frying tube with the need for cooking oil as much as 12 liters. Determination of the best temperature and time frying treatment from organoleptic test results with weighting test. In the organoleptic test, the panelists were asked for their opinions on their level of preference for the product of mango chips. Organoleptic tests in this study used 15 panelists with a preference test covering 4 quality parameters, namely aroma, taste, crispness, and color. The results of this study are the best treatment of temperature and time of frying for the manufacture of mango chips is a temperature of $90^{\circ} \mathrm{C}$ for 50 minutes. The questionnaire results showed that panelists tended to rank crispness in the first place (38\%), taste second $(33.33 \%)$, color in the third (29.33\%), and aroma in the fourth $(26.66 \%)$.

Keywords: vacuum frying, mango chips, temperature optimization

\section{PENDAHULUAN}

Mangga (Mangifera indica L.) merupakan buah andalan nasional yang dipasarkan dalam bentuk segar baik tujuan domestik maupun ekspor. Total produksinya meningkat dari tahun ke tahun hingga mencapai 2,3 juta ton pada tahun 2012 (http://faostat.fao.org/). Volume ekspor buah mangga selalu menurun dibandingkan dengan total produksinya karena kebutuhan konsumsi dalam negeri semakin tinggi. Akibatnya pada saat musim panen raya terjadi lonjakan produksi yang besar. Untuk mengatasi produksi yang berlimpah dan sifat buah mangga yang mudah rusak, maka dibutuhkan teknologi pengolahan dan penyimpanan agar masa distribusi lebih lama (Setyadjit et al., 2010). Kondisi ini dapat dimanfaatkan oleh petani mangga untuk meningkatkan nilai tambah, daya saing dan kesejahteraan melalui kegiatan diversifikasi produk olahan buah mangga. Menurut Setyadjit et al, (2010) dari Balai Besar Penelitian dan Pengembangan Pascapanen Pertanian bahwa cara mendapatkan keripik buah dengan mutu tinggi adalah menggunakan mesin penggorengan vacuum frying. Kelebihannya antara lain keripik buah tidak gosong, kandungan nutrisi tidak hilang, rasa dan aroma sesuai bahan aslinya, renyah, tidak perlu bahan pengawet dan penambah rasa buatan. Sehingga diperlukan analisis teknologi tepat guna yang membahas pengaruh optimalisasi suhu dan waktu mesin vacuum frying terhadap peningkatan kualitas keripik mangga Situbondo.

Untuk menggoreng buah-buahan yang akan dijadikan keripik dibutuhkan sebuah alat yang dinamakan vacuum fryer ( mesin penggoreng hampa ). Kita tidak mungkin menghasilkan produk buah olahan berupa keripik dengan menggunakan alat penggoreng biasa. Seperti diketahui untuk komoditi buah-buahan hampir semuanya memiliki 
kandungan glukosa ( gula ) yang cukup tinggi. Karenanya, bila kita mengolahnya dengan cara menggoreng menggunakan alat penggoreng biasa, buah yang kita goreng akan meleleh seperti jeli atau menjadi gosong dan tidak layak untuk dijual maupun dikonsumsi. Lain halnya bila kita menggunakan pengorengan vacuum, hasilnya akan lebih bagus, keripik tidak gosong, tetap cerah seperti warna aslinya dan kandungan vitamin dari buah olahan tidak rusak.

Selain itu, kerusakan aroma dan rasa dapat dihindari karena suhu penggorengannya lebih rendah dari suhu penggorengan pada satu atmosfir. Hal ini disebabkan karena proses penggorengan dilakukan pada tekanan dibawah satu atmosfir, sehingga menurunkan titik didih air. Akibat dari penurunan titik didih air tersebut, kita bisa melakukan penggorengan dengan suhu yang lebih rendah.

\section{Keripik Mangga}

\section{TINJAUAN PUSTAKA}

Keripik adalah makanan ringan (snack food) yang tergolong jenis makanan crackers, yaitu makanan yang bersifat kering, renyah (crispy). Keripik mempunyai sifat renyah, tahan lama, praktis, mudah dibawa dan disimpan, (Sulistyowati 1999). Buah mangga dapat diolah menjadi produk keripik yang mempunyai nilai jual yang lebih tinggi dari buah mangga segar. Sebagai produk olahan, rasa khas dapat dinikmati setiap waktu karena sudah menjadi produk yang awet.

Berdasarkan hasil penelitian yang dilakukan Ai Winarti (2000), yaitu studi pengaruh suhu dan waktu penggorengan keripik mangga. Pengamatan meliputi kadar air, kadar lemak dan vitamin $\mathrm{C}$ dengan mengambil sampel suhu $85^{\circ} \mathrm{C}, 90^{\circ} \mathrm{C}$, dan $95^{\circ} \mathrm{C}$, waktu penggorengan 15 - 35 menit dengan ketebalan rata-rata irisan mangga 2,13 mm diperoleh bahwa:

1. Kadar air rata-rata keripik mangga berkisar antara $1,93-2,86 \%$. Peningkatan suhu dan waktu penggorengan dapat menurunkan kadar air keripik mangga.

2. Kadar lemak rata-rata berkisar antara 32,58 - 39,98\%. Peningkatan suhu dan waktu dapat menaikkan kadar lemak keripik mangga.

3. Vitamin C rata-rata berkisar antara 1,841-3,457 mg/g. Peningkatan suhu dan waktu penggorengan dapat menurunkan nilai vitamin $\mathrm{C}$ keripik mangga.

4. Produk yang dianggap paling baik adalah produk yang digoreng pada suhu selama 35 menit. Pada kondisi ini, keripik mangga yang dihasilkan lebih kering, tidak gosong, lebih renyah dan nutrisinya dianggap baik.

\section{Penggorengan Keripik Buah}

Penggorengan merupakan proses panas yang mempergunakan minyak sebagai media pindah kalor (Lastriyanto, 2004). Proses penggorengan merupakan proses menguapkan air yang terdapat pada bahan baku dengan mendidihkan media penguap (minyak goreng) pada temperatur tertentu yang juga memerlukan sejumlah kalor tertentu dalam proses penguapan tersebut (Ramdhani, 2004). Tujuan penggorengan adalah untuk membentuk karakteristik warna, aroma dan cita rasa, mengawetkan produk dan meningkatkan daya cerna (Lastriyanto, 2004). Selama ini alat yang dipakai untuk menggoreng keripik buah dan sayur adalah vacuum fryer, yaitu penggorengan dilakukan pada ruang vakum. Alat ini berfungsi untuk mengolah buah-buahan dan sayuran yang memiliki kadar air tinggi menjadi keripik buah dan sayur yang kering dengan tetap 
mempertahankan warna, aroma, dan cita rasa alami buah dan sayur. Adapun buah yang biasa diolah adalah nangka, apel, pepaya, nanas, salak, waluh, pisang, rambutan, mangga, labu kuning dan melon. Jenis sayuran seperti jamur tiram, buncis, kacang tanah, jagung, wortel dan kacang panjang.

Agar dapat dilakukan penggorengan pada buah dan sayur, penggorengan dilakukan pada tekanan dan temperatur rendah. Berbeda dengan penggorengan pada umumnya yang dilakukan pada tekanan atmosfir dan temperatur diatas $175^{\circ} \mathrm{C}$, proses penggorengan vakum dilakukan pada tekanan $10 \mathrm{kPa}$ (absolut) pada suhu $80-90^{\circ} \mathrm{C}$, dan lama penggorengan 60 - 100 menit (Lastriyanto 2004). Penggorengan vakum merupakan cara pengolahan yang tepat untuk menghasilkan kripik buah dan sayur dengan kualitas tinggi. Dengan teknologi ini, buah dan rsayur yang harganya jatuh pada musim panen dapat diolah menjadi keripik sehingga memiliki harga jual tinggi. Penggorengan dengan vacuum frying akan menghasilkan keripik dengan warna dan aroma buah asli serta lebih renyah. Kerenyahan tersebut diperoleh karena proses penurunan kadar air dalam buah terjadi secara berangsur-angsur (Lastriyanto, 2004).

\section{Penggorengan Hampa (Vacuum Frying)}

Menggoreng hampa adalah menggoreng berbagai macam produk dengan kondisi hampa udara. Menurut Lastriyanto (2006), penggorengan hampa dilakukan dalam ruangan tertutup dengan kondisi tekanan rendah sekitar $70 \mathrm{cmHg}$. Penggorengan hampa udara dapat digunakan sebagai alternatif pengolahan bahan yang rentan terhadap suhu yang tinggi. Bahan dipanaskan dibawah tekanan vakum sehingga menurunkan titik didih air dalam bahan (Muchtadi, 2008). Dengan penurunan tekanan maka suhu penggorengan bisa dilakukan relatif lebih rendah dibandingkan suhu penggorengan dengan tekanan atmosfer.

Beberapa keuntungan yang diperoleh dengan penggorengan hampa adalah warna, rasa,dan aroma tidak banyak berubah, kandungan seratnya tinggi, tahan lama meskipun tidak mempergunakan bahan pengawet (Lastriyanto, 2006). Pada kodisi vakum suhu penggorengan dapat diturunkan sebesar $50^{\circ} \mathrm{C}-60^{\circ} \mathrm{C}$ atau $5-6$ dekade, karena penurunan titik didih air. Dengan demikian produk yang mengalami kerusakan warna, aroma, rasa, dan nutrisi akibat panas dapat diproses dengan teknologi ini. Di sisi lain kerusakan minyak dan akibat-akibat yang ditimbulkan dapat diminimumkan karena proses dilakukan pada suhu dan tekanan rendah (Lastriyanto, 2006).

Keunggulan mesin vacuum frying dapat disimpulkan sebagai berikut:

1. Hasil gorengan keripik tidak berubah dari warna aslinya

2. Aroma dan rasanya pun tidak berubah dari buah maupun sayur yang asli

3. Tidak perlu tambahan Rasa, No Perisa, NO MSG

4. Hasil gorengan keripik lebih renyah

5. Material bahan mesin aman untuk makanan (food grade)

6. Kandungan nutrisi dalam produk tidak hilang

7. Produk hasil mesin ini tidak mudah tengik, jadi lebih awet bahkan tanpa bahan pengawet

8. Tidak gosong 


\section{Penelitian Tentang Penerapan Vacuum Frying Dalam Pembuatan Keripik}

Penggorengan hampa telah banyak diteliti dan diterapkan dalam penggorengan keripik seperti keripik buah, jamur, dan ikan. Biasanya setiap produk pangan memiliki suhu dan waktu penggorengan yang berbeda jika digoreng hampa. Menurut Lastriyanto (1997) dalam Paramita (1999), penggorengan hampa dilakukan dalam ruangan tertutup dengan kondisi tekanan rendah dimana kondisi yang baik untuk buah secara vakum adalah suhu $90^{\circ} \mathrm{C}$, tekanan $0.7 \mathrm{cmHg}$ dan waktu penggorengan 1 jam.

Garayo (2001), membandingkan keripik kentang yang digoreng pada suhu $\left(118,132,144^{\circ} \mathrm{C}\right)$ dan tekanan hampa $(16.66,9.89$, dan $3.12 \mathrm{kPa})$ dengan keripik kentang goreng dalam kondisi atmosfer $\left(165^{\circ} \mathrm{C}\right)$. Ternyata keripik dengan penyerapan minyak terendah dengan kualitas produk seperti penyusutan, warna, dan tekstur terbaik didapatkan pada keripik kentang yang digoreng pada kondisi suhu $144{ }^{\circ} \mathrm{C}$ dengan tekanan hampa $3.12 \mathrm{kPa}$.

Menurut Paramita (1999) dalam judul penelitiannya "Pengaruh suhu dan waktu penggorengan hampa terhadap sifat fisik dan organoleptik keripik sawo (achras sapota)", disimpulkan bahwa keripik sawo terbaik diperoleh pada penggorengan hampa dengan suhu $95^{\circ} \mathrm{C}$ dengan waktu 40 menit. Paramita(1999), melakukan penelitian terhadap suhu $85^{\circ} \mathrm{C}, 90^{\circ} \mathrm{C}, 95^{\circ} \mathrm{C}$ dan waktu 35 menit , 40 menit, 45 menit dengan tekanan $65 \mathrm{cmHg}$.

Selain itu Wijayanti (2011) dalam judul penelitiannya "Kajian Rekayasa Proses Penggorengan Hampa dan Kelayakan Usaha Produksi Keripik Pisang" melakukan penelitian pada suhu $60^{\circ} \mathrm{C}, 70^{\circ} \mathrm{C}, 80^{\circ} \mathrm{C}, 90^{\circ} \mathrm{C}$ dan waktu 30 menit, 45 menit, 60 menit, dan 75 menit dihasilkan keripik pisang yang disukai panelis pada kondisi optimum yaitu suhu $80^{\circ}$ selama 60 menit pada tekanan $70 \mathrm{cmHg}$.

Sedangkan penelitian mengenai suhu dan waktu yang terbaik untuk memperoleh keripik mangga indramayu (Mangifera indica L.) dilakukan oleh winarti (2000). Pada penelitian utama dilakukan penggorengan hampa pada suhu $85^{\circ} \mathrm{C}, 90^{\circ} \mathrm{C}, 95^{\circ} \mathrm{C}$ serta waktu penggorengan 15 menit, 25 menit, dan 35 menit dan dihasilkan produk keripik mangga terbaik pada penggorengan dengan suhu $85^{\circ} \mathrm{C}$ dengan waktu 35 menit.

Menurut Rosyanti (2000) dalam judul penelitiannya "Optimisasi suhu dan waktu penggorenganhampa jamur tiram (Pleurotus ostreatus)" melakukan penggorengan hampa pada suhu $100^{\circ} \mathrm{C}, 105^{\circ} \mathrm{C}, 110^{\circ} \mathrm{C}$ pada waktu penggorengan $6,10,15$ menit pada tekanan $70 \mathrm{cmHg}$. Dari penelitian pendahuluan diperoleh produk terbaik pada kondisi penggorengan $105^{\circ} \mathrm{C}$ selama 15 menit.

Dalam penelitiannya Sudjud (2000), melakukan penelitian utama pada penggorengan hampa buah cempedak pada suhu $85^{\circ} \mathrm{C}, 90^{\circ} \mathrm{C}, 95^{\circ} \mathrm{C}$ dengan waktu penggorengan 25 menit, 30 menit, dan 35 menit dengan tekanan $10 \mathrm{cmHg}$ diperoleh keripik cempedak terbaik pada penggorengan hampa pada suhu $90^{\circ} \mathrm{C}$ selama 30 menit.

Begitu juga dengan Nurhudaya (2011), diperoleh suhu dan waktu yang optimal untuk penggorengan hampa durian menjadi keripik durian berdasarkan hasil pembobotan adalah $75^{\circ} \mathrm{C}$ dan 85 menit.

Sedangkan untuk penggorengan hampa ikan balita diperoleh suhu dan waktu yang optimal adalah $105^{\circ} \mathrm{C}$ dan 30 menit (Suseno dkk, 2008). 


\section{METODE PENELITIAN}

Metode penelitian yang digunakan dalam penelitian ini adalah metode experimental nyata (true experimental research). Jenis penelitian ini mempunyai tujuan untuk mengetahui hubungan yang terjadi antar faktor atau variabel-variabel yang ada, dengan cara memberi perlakuan kepada satu atau lebih kelompok eksperimental dengan kondisi perlakuan yang berbeda-beda. Penelitian ini dilaksanakan di Laboratorium Permesinan Program Studi Teknik Mesin Universitas Muhammadiyah Jember Jalan Karimata No. 49 Jember pada bulan November 2017.

Alat yang digunakan dalam penelitian ini adalah mesin vacuum frying kapasitas 2 $\mathrm{kg}$ bahan dengan spesifikasi sebagai berikut:

\section{Tabel 1. Spesifikasi Mesin Vacuum Frying}

\begin{tabular}{|l|c|}
\hline Dimensi Mesin & 9800 mm x 710 mm x 1150 \\
\hline Bahan Material & $\begin{array}{c}\text { Stainless Steel Anti Karat } \\
\text { Berstandar Food Grade }\end{array}$ \\
\hline $\begin{array}{c}\text { Tebal Bahan Tabung } \\
\text { Penggorengan }\end{array}$ & $2 \mathrm{~mm}$ \\
\hline Waktu Masak & 30 menit - 50 menit \\
\hline Fitur Pengontrol Suhu & $\begin{array}{c}\text { Otomatis ( Automatic } \\
\text { Thermostat Control ) }\end{array}$ \\
\hline Pemanas & $\begin{array}{c}\text { Kompor ( Tungku ) Gas } \\
\text { LPG Rinnai R1 - 511E }\end{array}$ \\
\hline Bahan Bakar & LPG ( Liquid Petroleum \\
& Gas) \\
\hline Kapasitas Minyak & Sirkulasi Air \\
\hline Sistem Pendingin & \begin{tabular}{c} 
\pm 250 Liter \\
\hline Kapasitas Air Pendingin
\end{tabular} \\
\hline Daya & Vacuum Frying \\
\hline Sistem & (Menggoreng Dengan Hampa \\
& Udara) \\
\hline Penggerak Vakum & inch \\
\hline
\end{tabular}

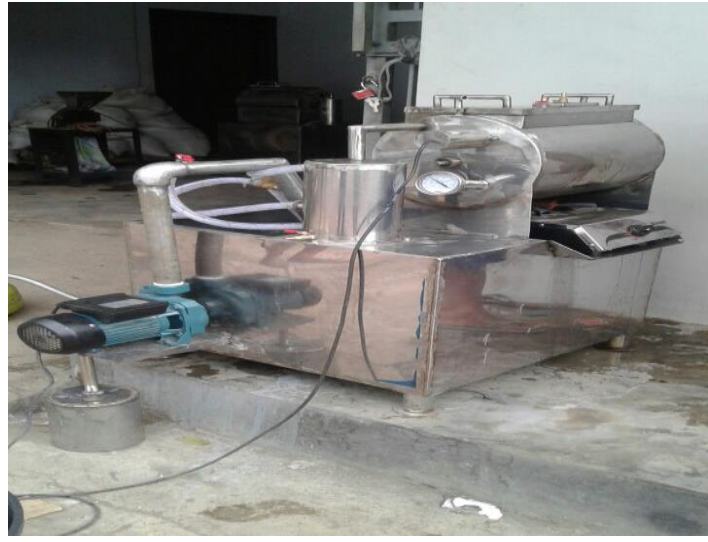

Gambar 1. Mesin Vacuum Frying Kapasitas $2 \mathrm{Kg}$ Bahan 


\section{Konsep Perancangan Vacuum Frying}

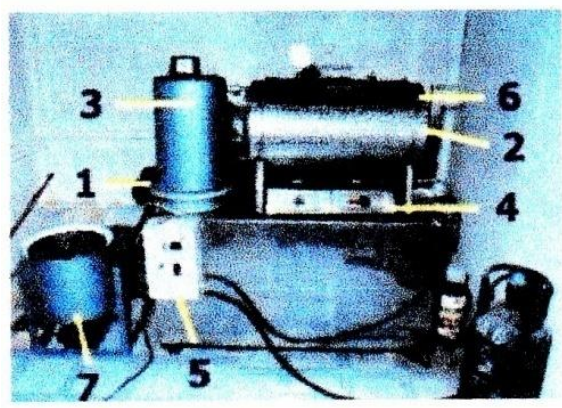

Gambar 2. Mesin Penggoreng Hampa Dan Komponen-Komponennya

Bagian-bagian penting dari mesin penggoreng hampa diatas adalah:

1. Pompa Vakum Water jet, berfungsi untuk menghisap udara di dalam ruang penggoreng sehingga tekanan menjadi rendah, serta untuk menghisap uap air bahan.

2. Tabung Penggoreng, berfungsi untuk mengkondisikan bahan sesuai tekanan yang diinginkan. Di dalam tabung dilengkapi keranjang buah setengah lingkaran.

3. Kondensor, berfungsi untuk mengembunkan uap air yang dikeluarkan selama penggorengan. Kondensor ini menggunakan air sebagai pendingin.

4. Unit Pemanas, menggunakan kompor gas LPG.

5. Unit Pengendali Operasi (Boks Kontrol), berfungsi untuk mengaktifkan alat vakum dan unit pemanas.

6. Bagian Pengaduk Penggorengan, berfungsi untuk mengaduk buah yang berada dalam tabung penggorengan.

7. Mesin pengering (spinner), berfungsi untuk meniriskan kripik

\section{Mekanisme Kerja Vacuum Frying}

1. Bahan yang dimasukkan ke dalam penggorengan vacuum akan digoreng secara vacuum. Penggorengan secara vacuum ini akan membuat kadar air di dalam buah akan dikeluarkan dan digantikan oleh minyak. Dengan suhu penggorengan rata-rata yang digunakan berkisar $70-90^{\circ} \mathrm{C}$ dan tekanan bisa mencapai $76 \mathrm{cmhg}$, dengan lama penggorengan antara 40 menit sampai 120 menit (perlakuan ini tergantung jenis dan karakteristik buah). Karena setiap buah memiliki kadar air dan tekstur daging buah yang berbeda. Karena penggorengan dengan mesin vacuum frying ini bisa menurunkan titik didih di bawah $90^{\circ} \mathrm{C}$, maka hasil keripik tidak akan sampai gosong.

2. Untuk menggoreng dibutuhkan minyak goreng sekitar 12 liter. Dengan adanya penurunan titik didih di bawah $90^{\circ} \mathrm{C}$ pada penggorengan maka struktur kandungan minyak goreng tidak cepat rusak, sehingga minyak goreng bisa digunakan untuk menggoreng kripik hingga mencapai 100 kali penggorengan. Dengan demikian bisa menghemat penggunaan minyak goreng.

3. Untuk hasil yang terbaik sebaiknya menggunakan minyak goreng yang bermerk dan jernih, karena minyak goreng yang kualitasnya rendah akan mempengaruhi warna dan aroma keripik buah. Buah yang dibuat dengan mesin vacuum frying bisa bertahan untuk layak konsumsi hingga setengah tahun, dan ini juga tergantung kualitas akan kemasannya. 


\section{Prosedur Pengolahan Keripik Mangga}

1. Isi bak air sampai $\pm 3 \mathrm{~cm}$ dari permukaan bak sirkulasi.

2. Masukkan minyak goreng ke dalam tabung sampai dasar keranjang buah.

3. Pastikan tombol pengendali suhu pada posisi off sewaktu menghubungkan regulator LPG dengan tabung.

4. Periksa kedudukan jarum penyetel suhu pada $70^{\circ} \mathrm{C}-90^{\circ} \mathrm{C}$, kemudian hubungkan steker boks pengendali suhu dengan listrik 220 volt, minimal 900 Watt.

5. Tekan tombol pengendali suhu pada posisi on dan nyalakan kompor gas.

6. Setelah tercapai suhu yang di set (ditandai nyala kompor mengecil), masukkan bahan maksimum sebanyak $2 \mathrm{~kg}$ ke dalam keranjang penggoreng kemudian tutup.

7. Pasang tutup tabung penggoreng dan kunci rapat-rapat, tutup keran pelepas vakum, nyalakan pompa dengan menekan tombol besar dalam posisi on pada boks pengontrol sambil membuka keran sirkulasi air di atas tabung jet, tunggu hingga air keluar dari selang bagian atas kondensor.

8. Setelah vacuum meter meter menunjukkan angka $700 \mathrm{mmHg}$, turunkan keranjang ke dalam minyak dengan memutar tuas pengaduk setengah putaran $\left(180^{\circ} \mathrm{C}\right)$. Goyanglah tuas setiap 5 menit untuk meratakan pemanasan.

9. Pada saat bahan dimasukkan ke dalam minyak, suhu akan turun, jarum meter vakum bergerak ke kanan, kaca pengintai menjadi berembun.

10. Setelah matang, buih pada tabung penggorengan akan hilang (dilihat dari kaca pengintai dengan menekan tombol lampu ke posisi on), angkat bahan ke atas minyak dengan memutar tuas pengaduk $180^{\circ}$ dan kunci. Matikan pompa, kompor, dan keran sirkulasi air, kemudian buka keran pelepas vakum (di atas tutup), hingga vacuum meter menunjuk angka 0 .

11. Buka tutup tabung dan keranjang penggoreng, angkat keripik buah dan tiriskan pada mesin pengering.

\section{Rancangan Penelitian Utama}

Adapun variabel yang akan diamati adalah sebagai berikut:

1. Variabel bebas yaitu variabel yang bebas diambil, yang telah ditentukan oleh peneliti. Adapun variabel tersebut adalah suhu dan waktu penggorengan.

2. Variabel terikat (tidak bebas) yaitu variabel yang nilai tergantung dari variabel bebas yang telah ditentukan. Dalam hal ini variabel terikatnya adalah kualitas keripik mangga.

Rancangan penelitian terdiri dari tiga perlakuan dengan dua kali ulangan. Penelitian menggunakan 2 faktor yaitu suhu dan waktu penggorengan dengan lima kali ulangan. Faktor suhu memiliki 3 taraf (level), yaitu $70^{\circ} \mathrm{C}, 80^{\circ} \mathrm{C}$ dan $90^{\circ} \mathrm{C}$. Faktor waktu juga memiliki 3 level, yaitu 30 menit, 40 menit dan 50 menit.

\section{Tahap Penelitian}

Penelitian yang dilaksanakan terdiri dari penelitian pendahuluan dan penelitian utama. Tujuan dari penelitian pendahuluan adalah untuk menentukan rentang suhu dan waktu yang optimal yang digunakan dalam proses penggorengan. Hasil terbaik dari penelitian pendahuluan tersebut digunakan pada penelitian utama.

Penelitian dilakukan dengan 2 tahap yaitu penelitian pendahuluan dan penelitian utama. Penelitian pendahuluan dilakukan untuk mengetahui kisaran suhu dan waktu penggorengan keripik mangga. Pengamatan yang dilakukan pada penelitian pendahuluan adalah pengamatan warna dan kerenyahan keripik mangga secara subjektif.

Percobaan pada penelitian pendahuluan ini akan dilakukan secara trial and error. Pada penelitian pendahuluan dilakukan penggorengan hampa pada suhu $60^{\circ} \mathrm{C}$ hingga 100 
${ }^{\circ} \mathrm{C}$ dan waktu penggorengan selama 20 menit hingga 60 menit dengan kapasitas masuk per prosesnya adalah $2 \mathrm{~kg}$. Perlakuan ini dikembangkan lagi pada beberapa taraf pada penelitian utama. Pada penelitian utama, hasil penelitian pendahuluan dikembangkan lebih lanjut pada berbagai tingkat suhu dan waktu. Sehingga suhu dan waktu penggorengan yang terbaik diperoleh dari penelitian pendahuluan ini secara subjektif dari pengamatan warna dan kerenyahan keripik mangga adalah suhu $70^{\circ} \mathrm{C}, 80^{\circ} \mathrm{C}$, dan $90^{\circ} \mathrm{C}$ dengan waktu selama 30 menit, 40 menit, dan 50 menit.

\section{Teknik Pengambilan Data}

Dalam penelitian ini, peneliti menggunakan observasi langsung untuk teknik pengambilan data dari hasil penelitian yaitu suatu teknik atau metode pengumpulan data dengan cara mengadakan pengamatan secara langsung pada Mesin Vacuum Frying yang diuji dengan mencatat hasil pengamatan.

Penentuan perlakuan suhu dan waktu penggorengan yang terbaik dari hasil uji organoleptik dengan uji pembobotan. Uji organoleptik yang digunakan adalah uji hedonik (kesukaan), yang menyangkut penilaian beberapa orang panelis terhadap sifat produk. Pada uji organoleptik, panelis dimintai pendapatnya mengenai tingkat kesukaannya terhadap produk keripik mangga. Uji organoleptik pada penelitian ini menggunakan 15 orang panelis. Dalam uji ini, panelis diminta tanggapannya tentang kesukaan atau ketidaksukaannya. Pengujian ini menggunakan skor dengan tujuh skala kesukaan yaitu 7 (sangat suka), 6 (suka), 5 (agak suka), 4 (netral), 3 (agak tidak suka), 2 (tidak suka), dan 1 (sangat tidak suka). Parameter yang diuji secara organoleptik dari keripik mangga ini adalah rasa, warna, aroma, dan kerenyahan.

Panelis diberi kuesioner mengenai parameter organoleptik keripik yaitu warna, rasa, kerenyahan, dan aroma. Lalu panelis diminta untuk mengurut tiap parameter berdasarkan tingkat kepentingannya. Pengurutannya mulai dari $4=$ sangat penting, $3=$ penting, 2 = agak penting, dan $1=$ tidak penting.

\section{HASIL DAN PEMBAHASAN}

Penelitian ini dilakukan untuk mengetahui pengaruh suhu dan lama penggorengan terhadap parameter mutu dan organoleptik, serta menentukan suhu dan waktu penggorengan yang optimal dilihat dari uji pembobotan. Produk dengan penerimaan panelis tertinggi untuk rasa terdapat pada perlakuan $90^{\circ} \mathrm{C}$ selama 50 menit sedangkan yang terendah terdapat pada produk dengan perlakuan suhu $70^{\circ} \mathrm{C}$ selama 30 menit. Semakin tinggi suhu dan waktu penggorengan maka penilaian panelis untuk rasa keripik semakin tinggi. Dan untuk parameter aroma, nilai tertinggi juga terdapat pada produk dengan perlakuan penggorengan $90^{\circ} \mathrm{C}$ selama 50 menit, dan yang terendah terdapat pada produk dengan perlakuan penggorengan pada suhu $70^{\circ} \mathrm{C}$ selama 30 menit. Sedangkan untuk warna, dapat dilihat pada grafik bahwa nilai untuk semua perlakuan tidak jauh beda.

Dan untuk kerenyahan, nilai tertinggi terdapat pada produk dengan perlakuan penggorengan pada suhu $90^{\circ} \mathrm{C}$ selama 50 menit. Sedangkan yang terendah terdapat pada perlakuan dengan suhu $70^{\circ} \mathrm{C}$ selama 30 menit. Jika dilihat dari grafiknya, semakin tinggi suhu dan waktu penggorengan maka penilaian panelis terhadap kerenyahan semakin tinggi juga. Hal ini sesuai dengan nilai kadar air. Dimana semakin rendah kadar air, panelis semakin menyukai produk tersebut. Artinya semakin rendah kadar air, maka produk tersebut semakin renyah dan semakin banyak ruang kosong yang akan diisi oleh minyak. Sedangkan panelis lebih menyukai kerenyahan produk yang waktu 
penggorengannya selama 50 menit. Begitu juga nilai kerenyahan untuk semua produk dengan perlakuan penggorengan selama 50 menit, hampir tidak jauh beda.

\section{KESIMPULAN DAN SARAN}

Perlakuan suhu dan waktu penggorengan yang terbaik untuk pembuatan keripik mangga adalah suhu $90^{\circ} \mathrm{C}$ selama 50 menit. Hasil kuisioner menunjukkan bahwa panelis cenderung mengurutkan kerenyahan pada urutan pertama $(38 \%)$, rasa pada urutan kedua $(33.33 \%)$, warna pada urutan ketiga $(29.33 \%)$, dan aroma pada urutan keempat $(26.66 \%)$.

Perlu dilakukan pengkajian mutu produk keripik mangga yang dihasilkan pada suhu dan waktu penggorengan terbaik. Perlu dilakukan penelitian untuk menentukan jenis kemasan yang tepat agar produk keripik mangga dapat dipertahankan mutunya selama penyimpanan untuk jangka waktu tertentu.

\section{DAFTAR PUSTAKA}

Azkenazi N, S Mizrahi dan Z Berk. 1984. Heat and mass Transfer in frying. Di dalam B. M. Mc Kenna (ed.). Engineering and Food Vol. 1. Elsevier Apllied Science Publ., London

Block, Z. 1964. Frying. Di dalam M.A Joslyn dan J.J Heid (ed). Food Process Operation Vol 3. The AVI Publ. Co., Westport

Blumenthal MM. and Stier RF. 1991. Optimization off deep fat frying operations. Trend Food Sci

Desy Erizha Widya F. 2012. Pengaruh Waktu Dan Suhu Pada Pembuatan Keripik Nanas Dengan Vacuum Frying (The Effect of Time and Temperature on the Manufacture of Pineapple Chips with Vaccum Frying). Program Studi Diploma III Teknik Kimia Program Diploma Fakultas Teknik Universitas Diponegoro Semarang.

Djatmiko B, dan AB Enie.1985. Proses Penggorengan dan Pengaruhnya Terhadap Sifat Fisiko Kimia Minyak dan Lemak. Agro Industri Press. Jurusan Teknologi Industri Pertanian, Fatetat, IPB, Bogor

Eva Mayasari. Laporan Praktikum Penggorengan Keripik Buah

Garayo, J et al. 2001. Vacuum Frying of Potato Chips. Journal of Food Engineering, Volume 55, Issue 2, November 2002, Pages 181 -191

Hallstrom, B. 1980. Heat and Mass Transfer in Industrial Cooking di dalam P. Linko et al (eds) Food Process Enginering vol I. Applied Science Publ. London

Ignasius Lantip Waspodo Gayutomo. 2006. Optimasi Suhu Dan Waktu Vacuum Frying Dalam Peningkatan Kualitas Keripik Nangka (Artocarpus heterophylla Lamk).http://repository.unika.ac.id/IgnasiusLatipW.LAMPIRAN.pdf 
IP2TP Jakarta. 2000. Laporan Akhir Penelitian Adaptif Teknologi Pasca Panen BuahBuahan http://www.pustaka.litbang.deptan.go.id/agritek/dkij0122.pdf. [ 19 Februari 2011]

Irawan, R.S. 1992. Kajian Sifat Fisik dan Thermal dalam Fenomena Transport Proses Penggorengan Pangan. Skripsi FATETA IPB, Bogor

Keenan, J.H., F.G. Keyes, P.G. Hill, and J.G. Moore, 1978, Steam Tables. Thermodynamic properties of water including vapour, liquid and solid phases, Jhon wiley \& sons, New York, pp.134-138

Ketaren S.1986. Pengantar Teknologi Minyak dan Lemak Pangan. Jakarta : UI-Press

Lastriyanto A.1997. Penggorengan Buah secara Vakum (Vacuum Frying) dengan Menerapkan Pemvakuman Water Jet. Temu Ilmiah serta Ekspos Alat dan Mesin Pertanian. Cisarua-Bogor, 27 Februari 1997

Lastriyanto A. 2006. Mesin Penggorengan Vakum (Vacuum Fryer). Malang.

Lastrindo Engineering Lawson, H. 1995. Food Oils and Fats. Chapman and Hall Thomson Publ. Co., New York

Muchtadi TR. 2008 . Teknologi Proses Pengolahan Pangan. 3 rd ed. Bogor : Institut Pertanian Bogor.

Mustafa Anwar. 2013. Pengolahan Keripik Nanas. Bengkel Teknologi Industri Pertanian

Nurhudaya. 2011. Rekayasa Penggorengan Vakum dan Pengemasan Keripik Durian Mentawai. Skripisi Fakultas Teknologi Pertanian, IPB, Bogor

Oktavianus Manurung. 2011. Pengaruh Suhu dan Waktu Penggorengan Hampa terhadap Mutu Keripik Ikan Lemuru (Sardinella Longiceps). Skripisi Fakultas Teknologi Pertanian, IPB, Bogor

Paramita ND. 1999. Pengaruh Suhu dan Waktu Penggorengan Hampa (Vacuum Frying) terhadap Sifat Fisik dan Organoleptik Keripik Sawo (Achras sapota, L.). Skripisi Fakultas Teknologi Pertanian, IPB, Bogor

Robertson GL.1993. Food Packaging Principles and Practice. New York: Marcel Dekker, Inc

Rossel, J.B. 2001. Frying. Woodhead Publishing Limited, Abington Hall, Abington, Cambridge, England

Rosyanti, R.S. 2000. Optimasi suhu dan waktu penggorengan hampa jamur tiram (Pleurotus ostreatus). Skripisi Fakultas Teknologi Pertanian, IPB, Bogor 
Subekti A. 1993. Mempelajari Pembuatan Keripik Pepaya (Carica papaya L.) dengan sistem Penggorengan Vakum [skripsi]. Fakultas Teknologi Pertanian, Institut Pertanian Bogor

Sudjud HR. 2000. Mempelajari pengaruh suhu dan waktu penggorengan hampa terhadap sifat fisik dan Organoleptik keripik buah cempedak (Artocarpus integer (Thunb) Merr). Skripisi Fakultas Teknologi Pertanian, IPB, Bogor

Suseno SH, Jajang SM, Asra. 2008. Penerapan teknologi Vacuum Frying bagi kelompok tani pengolah ikan di kabupaten Tasikmalaya dalam rangka pengembangan produk unggulan daerah. Laporan program penerapan IPTEKS, Lembaga penelitian dan pengabdian kepada, masyarakat, IPB, Bogor

Yuniarto K.. 2007. Korelasi nisbih fraksi kentang terhadap volume minyak dengan penurunan mutu fisik dan kimia minyak selama penggorengan hampa. Jurnal Teknologi Pertanian 8 (2): 103-109

Winarti, 2000. Pengaruh suhu dan waktu penggorengan hampa terhadap mutu keripik mangga Indramayu (Mangifera indica L.). Skripisi Fakultas Teknologi Pertanian, IPB, Bogor.

http://www.pustaka.litbang.deptan.go.id/agritek/dkij0122.pdf 